\title{
On the nature of carbon embrittlement of tungsten fibers during
}

\section{powder metallurgical processes}

\author{
Y. Mao a , C.Chen ${ }^{\mathrm{e}^{*}}$, J.W. Coenen ${ }^{\mathrm{a}}$, J. Riesch ${ }^{\mathrm{b}}$, S. Sistla ${ }^{\mathrm{c}}$, J. Almanstötter ${ }^{\mathrm{d}}$, A. Terra ${ }^{\mathrm{a}}$, Y. Wu ${ }^{\mathrm{e}, \text { f }}$, L.

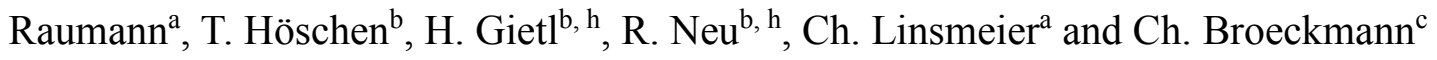 \\ ${ }^{a}$ Forschungszentrum Jülich GmbH, Institut für Energie- und Klimaforschung - Plasmaphysik, \\ Partner in the Trilateral Euregio Cluster, 52425 Jülich, Germany \\ ${ }^{b}$ Max-Planck-Institut für Plasmaphysik, 85748 Garching b. München, Germany \\ ${ }^{c}$ Institut für Werkstoffanwendungen im Maschinenbau (IWM), RWTH Aachen University, 52062 \\ Aachen, Germany \\ ${ }^{d}$ OSRAM GmbH, SP PRE PLM DMET, Mittelstetter Weg 2, 86830 Schwabmünchen, Germany \\ ${ }^{e}$ School of Materials Science and Engineering, Hefei University of Technology, Hefei 230009,
}

\section{China}

${ }^{f}$ China International S\&T Cooperation Base for Advanced Energy and Environmental Materials, Hefei 230009, China

${ }^{h}$ Technische Universität München, Boltzmannstr. 15, 85748 Garching, Germany

Correponding author: chench@hfut.edu.cn (C.Chen)

Abstract. As a candidate material for plasma facing material in future fusion reactor, tungsten (W) fiber reinforced tungsten $\left(\mathrm{W}_{\mathrm{f}} / \mathrm{W}\right)$ composite has been recently developed. The crack resistance of $\mathrm{W}_{\mathrm{f}} / \mathrm{W}$ is proven to be significantly higher compared to normal tungsten. However, the W-fibers used always become embrittlement during the powder metallurgy (PM) processes. In order to understand this significant issue, in this work, a series of $\mathrm{W}_{\mathrm{f}} / \mathrm{W}$ composites have been prepared. Microstructural and mechanical studies revealed that microstructural and mechanical studies 
revealed that the nanosized carbides in the grains and the carbide-layer on the grain boundaries are formed during PM processes. Especially, the carbide-layer on the grain boundaries can cause the brittle fracture of those $\mathrm{W}$-fibers affected. Meanwhile, W-foil protection of the green body during the sintering process can reduce the carbon contamination effect and allows to preserve the ductility of the tungsten fibers used

Keywords: Tungsten fiber; Powder consolidation; Transmission electron microscopy (TEM); Carbides; Embrittlement

\section{Introduction}

For a future fusion reactor, with the harsh fusion environment and its high transient heat loads and neutron irradiation, cracks may cause severe problems when brittle W is used as first Wall material $[1,2] . \mathrm{W}_{\mathrm{f}} / \mathrm{W}$ composites are being developed relying on an extrinsic toughing principle [3-8] to overcome the intrinsic brittleness of tungsten. Recently, a process using field assisted sintering technology (FAST) and hot isostatic pressing (HIP) to produce $\mathrm{W}_{\mathrm{f}} / \mathrm{W}$ bulk material has been established. The desired pseudo ductile fracture behavior is achieved relying on the toughening mechanisms enabled by the incorporated fibers $[3-5,9]$. However, one of the main issues during the composite production is the fiber embrittlement. During the powder metallurgy processes, the tungsten fiber is prone to embrittlement. This phenomenon is not observed in $\mathrm{W}_{\mathrm{f}} / \mathrm{W}$ produced by chemical vapor deposition (CVD) [7, 10].

This degradation of the fiber ductility can be caused by the elevated temperature treatment coarsening the fiber grain structure or by the influence of impurities. Based on the study in [11], the potassium doped tungsten fiber could remain ductile even after annealing at $2273 \mathrm{~K}$ for $30 \mathrm{~min}$. The sintering temperatures of both FAST and HIP processes are lower than $2273 \mathrm{~K}$. Based on the fiber grain structure after FAST process [4], no large grains with abnormal grain growth (like the 
embrittled fiber in [11]) have been observed. This gives a strong hint that the impurities could plays a key role for the fiber embrittlement. The brittleness of tungsten has been found to be related with the presence of metalloids such as $\mathrm{C}, \mathrm{O}, \mathrm{N}, \mathrm{P}[12,13]$. Previous studies $[4,14]$ revealed that, when exposed to graphite during the production process, the tungsten fibers will behave brittle. In the case of a powder metallurgical process, this negative influence is avoided by protecting the sample with pure tungsten foils. This gives us the indication that the $\mathrm{C}$ impurities could be the main issue here.

It has been investigated in a previous study, that $\mathrm{C}$ impurities can increase the ductile-brittle transition temperature (DBTT) of W [15]. On the contrary, another study has claimed that the carbon can increase the grain boundary cohesion and decrease the DBTT of W [13]. Therefore, it is necessary to figure out the influence of carbon on the ductility of $\mathrm{W}$ and a further study should be carried out investigating the type of the formed carbide and their distribution in the W fibers. In this work, $\mathrm{W}_{\mathrm{f}} / \mathrm{W}$ composite is produced by using FAST and HIP processes. Carbon contamination in tungsten fiber reinforced tungsten material is studied based on the mechanical and microstructural characterization. Relying on a transmission electron microscope (TEM) analysis, the carbide impurities and the impurities distribution has been confirmed in the tungsten fiber after the sintering processes for the first time.

\section{Experiment}

The raw materials are pure tungsten powders (provided by OSRAM GmbH) with $5 \mu$ m average particle size (Fischer sub sieve sizer) and potassium doped short tungsten fibers (provided by OSRAM GmbH) with $2.4 \mathrm{~mm}$ length and $0.15 \mathrm{~mm}$ diameter. Relying on the extremely elongated drawing grain structure, the tungsten fibers show ductile properties and extremely high tensile strength ( 3000 MPa) [2, 16]. 
Before the consolidation process, an yttrium oxide layer is deposited on the tungsten fibers as interface material, similar to the process described in [3]. The coating thickness is $\sim 2 \mu \mathrm{m}$. Subsequently, the coated fibers are mixed with the tungsten powders by manual shaking in a vessel using a fiber mass fraction of $30 \%$. The mixture is then poured into the FAST mold or HIP capsule. In order to vary the carbon content, two different samples are produced by the FAST consolidation process in this study using different sintering mold systems similar to the process in [4]:

1) Between the sample and the mold surface, a graphite foil is placed, aiming to reduce the damage of the mold surface and to ease the sample removal process. This mold setup is the conventional setup for FAST process.

2) Instead of using a graphite foil, a tungsten foil with $20 \mu \mathrm{m}$ thickness is used to separate the powder-fiber mixture aiming to reduce the carbon contamination $[4,14]$.

During the consolidation process, the heating rate is $200 \mathrm{~K} / \mathrm{min}$; the holding temperature is $2173 \mathrm{~K}$ (the temperature is measured at the bottom of the semi-hollow punch); holding time is 4 minutes. A constant pressure of $60 \mathrm{MPa}$ is applied during the process [17]. The average cooling rate is $\sim 375$ $\mathrm{K} / \mathrm{min}$ from $2173 \mathrm{~K}$ to $673 \mathrm{~K}$. The sintering is performed in vacuum below $0.1 \mathrm{mbar}$. As result, coin shaped samples (20 mm diameter and $\sim 5 \mathrm{~mm}$ height) are produced.

Another sample is produced using the HIP process within a setup from the company FPSI (Temse, Belgium). The powder/fiber mixture is firstly pre-compacted uniaxially at $200 \mathrm{MPa}$ by hand pressing and then put into a tantalum capsule with $0.5 \mathrm{~mm}$ wall thickness. After vacuum seal welding, the tantalum capsule is consolidated in the HIP chamber. The structural material of the HIP chamber, the sample stage and heating elements are all made of graphite. The powder-fiber mixture was consolidated under high isostatic pressure (200 MPa) and temperature (1873 K) for 
$2 \mathrm{~h}$. The heating and cooling rate is $10 \mathrm{~K} / \mathrm{min}$. After consolidation, the HIP sample is cylindrical in shape with $\sim 18 \mathrm{~mm}$ diameter and $\sim 14 \mathrm{~mm}$ height.

The relative densities of the samples produced by FAST with graphite foil, tungsten foil and by HIP process are $\sim 93 \%, 92 \%$ and $98 \%$, respectively. The density measurement is based on the Archimedes principle.

In all cases, the microstructure of the composite material shows the typical $\mathrm{W}_{\mathrm{f}} / \mathrm{W}$ microstructure, as reported in $[4,5]$ : random distributed fibers could be observed in the matrix; and between the fiber and material, an yttria interface is visible. The tungsten fiber grain size is larger in all the sintered samples as mentioned in [4]. Similar grain size is represented for the two samples produced by SPS process, and for HIP produced sample, the fiber grain size is slightly smaller due to the lower sintering temperature.

To test the fracture behavior of the fiber and the composite, qualitative 3-point bending tests have been performed, similar to the tests in $[3,5]$. The bending samples dimension is $18 \times 2 \times 4 \mathrm{~mm}^{3}$ (length $\mathrm{x}$ width $\mathrm{x}$ thickness, manufactured by diamond wire cutting, (GS-1000 wire cutting machine, Sommer Präzisionstechnik) with a $\sim 2 \mathrm{~mm}$ deep notch. The notch is prepared by diamond wire cutting with a diameter of $0.04 \mathrm{~mm}$ followed by manual razor blade polishing. After the test, the fracture surface is analyzed by a scanning electron microscope (SEM). One sample is tested for each process.

\section{Results and discussion}

The force-displacement curve of the 3-point bending test and the corresponding fracture sections are shown in Figure 1. As expected, from the curves, typical pseudo ductile behavior with increased defect tolerance is observed very consistent with the previous studies [3-5]. From Figure 1 , the fiber fracture surface of the $\mathrm{W}_{\mathrm{f}} / \mathrm{W}$ produced by FAST with graphite foil and $\mathrm{W}_{\mathrm{f}} / \mathrm{W}$ produced 
by HIP shows a typical brittle cleavage fracture with clear river line pattern. One the other hand, for the $\mathrm{W}_{\mathrm{f}} / \mathrm{W}$ that was protected by tungsten foil during FAST process, half of the fibers show a knife edge shape pattern together with a necking effect. This is a typical fracture surface for the ductile tungsten fiber. The knife edge shape pattern could be caused by the grain bondary sliding of the elongated grains $[11,16]$. Back to the force displacement curves, one could notice a clear difference from the shape of the test curves. For the ductile fiber $\mathrm{W}_{\mathrm{f}} / \mathrm{W}$, the falloff in load is much smoother and has more steps. During the bending test, after the maximum load, the failure of the ductile fiber consumes more energy and allows higher displacement, so the slope of load decreasing is much slower than in the brittle case. The results correspond to the analysis in $[4,5]$. In order to check for the presence of tungsten carbides and their distribution in the $\mathrm{W}$-fiber after sintering, TEM analysis is applied. The TEM samples were prepared by focus ion beam (FIB) from the center area of the fibers. The TEM observation was conducted with a JEOL 2010 transmission electron microscope and the operated accelerating voltage is $200 \mathrm{KV}$. The high resolution TEM (HRTEM) was conducted on Tecnai G20 transmission electron microscope and the operated accelerating voltage is also $200 \mathrm{KV}$. 

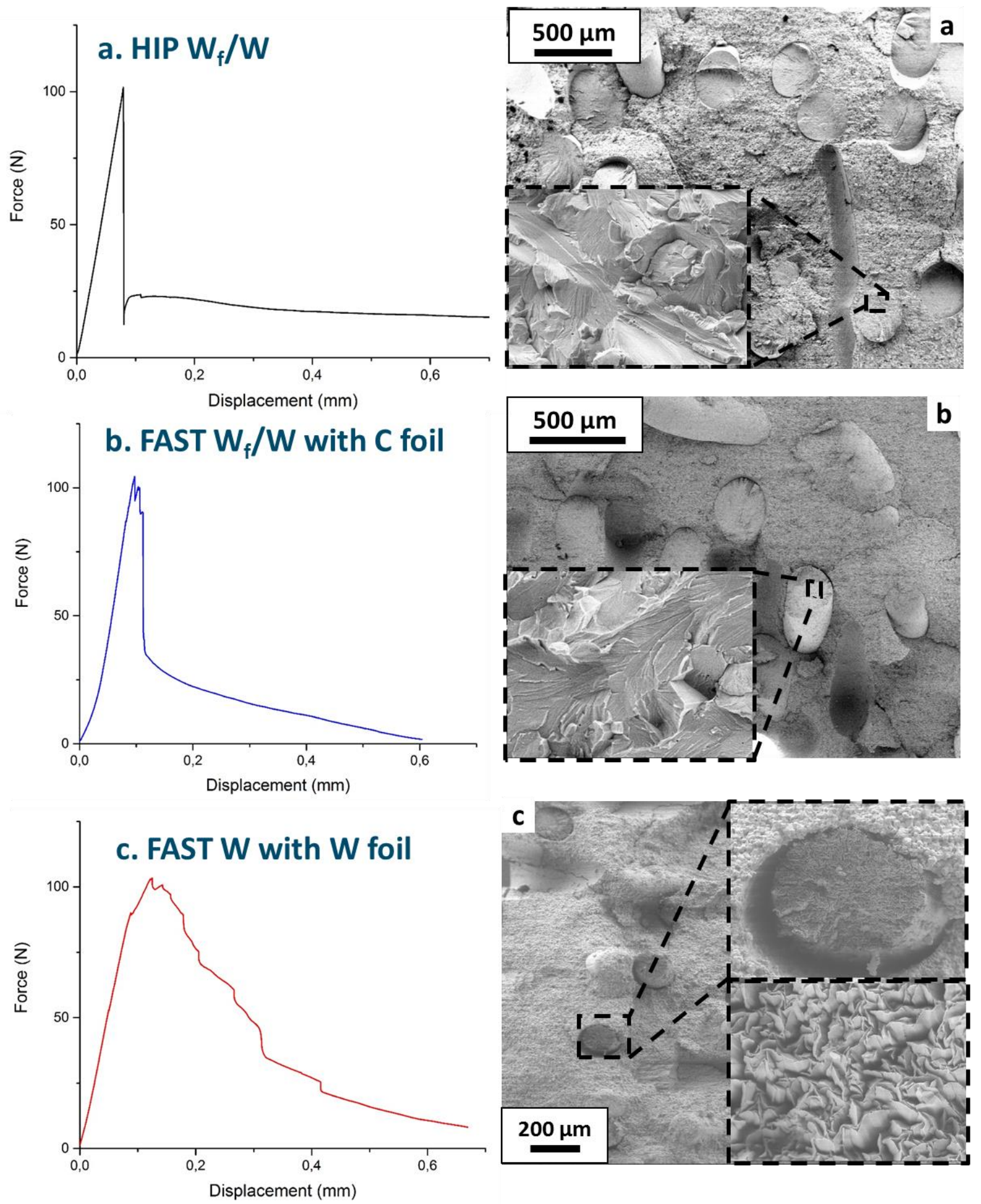

Figure 1. 3-point bending force-displacement curves and the corresponding fracture section of the $\mathrm{W}_{\mathrm{f}} / \mathrm{W}$ produced by HIP process, FAST process with graphite foil and FAST process with tungsten foil 
The typical TEM microstructures of the different samples are shown in Figure 2 together with selected area diffraction patterns (SADPs). It can be found that many nano-sized particles are formed in the $\mathrm{W}$-fiber within the grains without $\mathrm{W}$-foil protection. The TEM microstructure of the Hip samples is similar with that of the samples without $\mathrm{W}$-foil protection. The corresponding diffraction patterns from Fig. 2a show in addition to the diffraction patterns of the W crystal lattice, also other polycrystalline diffraction rings. Detailed evaluation shows that small carbide particles of $\mathrm{WC}_{1-\mathrm{x}}$ phase with a face centered cubic crystal structure are contributing to the diffraction rings. The lattice parameter of the $\mathrm{WC}_{1-\mathrm{x}}$ in these fibers is $0.410 \pm 0.015 \mathrm{~nm}$, which is similar to previous results [14]. On the opposite, the carbides and the diffraction rings cannot be observed in the fibers of the composites which are protected by tungsten foils, as shown in Figure $2 \mathrm{c}$ and $\mathrm{d}$. It can be inferred that the fibers in the samples protected by tungsten foils are not contaminated by the carbon from the graphite molds. During the HIP process, although the sample is covered by Ta capsule, the process time is much longer than FAST process ( $2 \mathrm{~h}$ holding time). The carbon from the graphite atmosphere (the sample stage and heating element) can diffuse through the Ta capsule, and trapped by the tungsten fibers.

Additionally, the interaction between the nanoparticles and dislocations can also be revealed at a higher magnification micrograph, as shown in Fig. 3. The mobility of dislocations will be reduced by pinning at the carbide particles during gliding. As consequence, this will lead to an increase in yield stress of the $\mathrm{W}$ fiber and a reduced dislocation mobility causing embrittlement. 

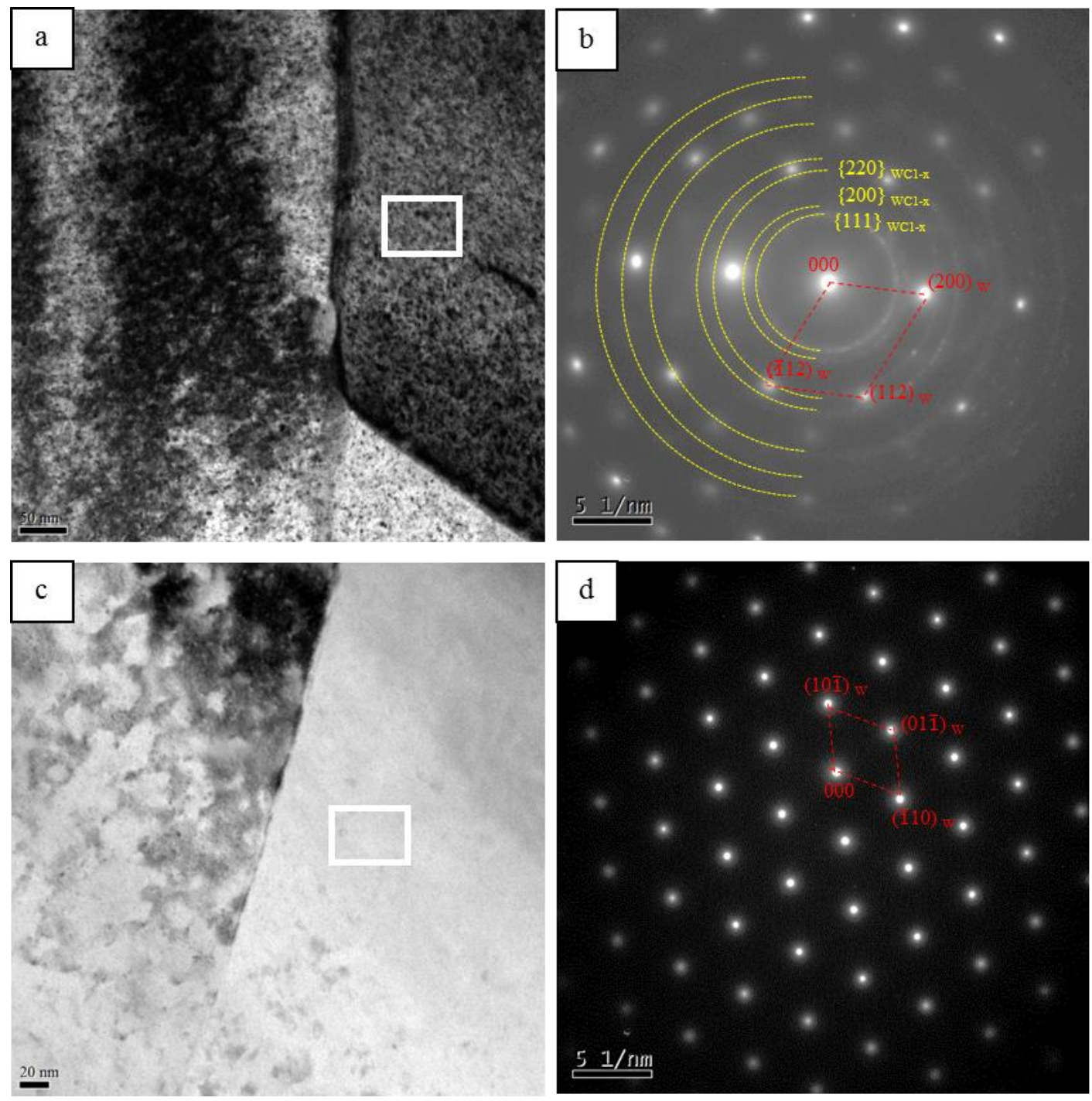

Figure 2. (a) The TEM micrographs of the tungsten fiber grain structure, the $\mathrm{W}_{\mathrm{f}} / \mathrm{W}$ sample is produced by FAST process with graphite foil and (b) the corresponding selected area diffraction patterns (SADPs) (b). (c) The TEM micrographs of the tungsten fiber grain structure; the $\mathrm{W}_{\mathrm{f}} / \mathrm{W}$ sample is produced by FAST process with tungsten foil and (d) the corresponding SADPs. Red indices mark $\mathrm{W}$ lattice planes, yellow indices show the contribution of $\mathrm{WC}_{1-\mathrm{x}}$ diffractions. 

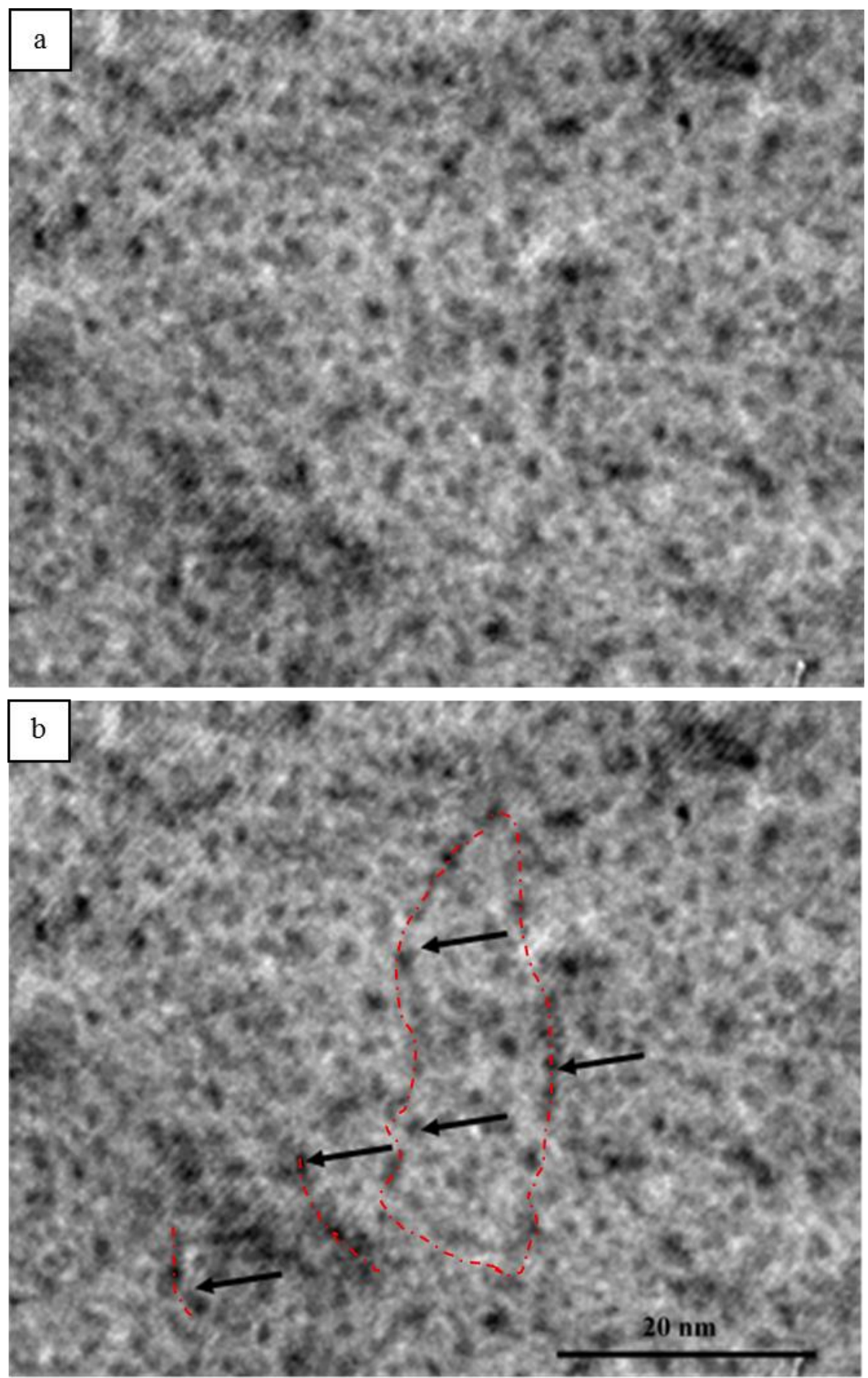

Fig. 3. TEM image showing the interaction between dislocations and carbides in the tungsten fiber. (a) Initial image, (b) image with marks, the lines show the dislocations and the arrows show the particles on the dislocations.

Besides, the carbides can also be seen on the grain boundaries. Different from the morphology in the grains, the carbides intend to form a thin continuous layer on the grain boundary, as shown in 
Fig. 4a. It can be found that a lot of nano-sized particles with different orientation are developed in the carbide layer, as shown by the dashed lines in Fig. 4b. The polycrystalline of the carbides in the layer can also be proven by the fast fourier transformation (FFT) diffractograms (Fig. 4c), in which the diffraction rings can be seen besides the diffraction patterns from the $\mathrm{W}$ matrix along [100] crystal zone. Moreover, the diffraction rings can be determined to be from the WCx. The crystalline spacing of the two rings is calculated to be $D_{1}=0.344 \mathrm{~nm}, \mathrm{D}_{2}=0.262 \mathrm{~nm}$, which are corresponding to the crystal planes (210), and (222) of $\mathrm{WC}_{\mathrm{x}}$.

The carbide layer on the grain boundary is very brittle. As shown in Fig. 4a, microcracks can be seen on the carbide layer. Meanwhile, the gliding dislocations can be jammed by the carbide layer. The piled-up dislocations can create stress concentration which cannot be released by the plastic deformation of the carbide layer. Therefore, microcracks are easily nucleated at this sites. This result contradicts recent theoretical considerations [18] and shows that model assumptions of single monolayers of carbon on tungsten grain boundaries resulting in enhanced cohesion cannot be confirmed by our experiments. Therefore, the embrittlement of $\mathrm{W}$ can result from two aspects: 1) the yield stress of $\mathrm{W}$ is improved since the mobility of dislocations is reduced by the particles in the grains. 2) the fracture stress of $\mathrm{W}$ is decreased since the cohesion of the grain boundaries is weakened by the carbide layer on the grain boundaries.

Furthermore, for the W-C system, it has been found that different kinds of carbides, such as WC and $\mathrm{W}_{2} \mathrm{C}$, can be formed at different condition [19]. According to the $\mathrm{W}-\mathrm{C}$ phase diagram, $\mathrm{W}_{2} \mathrm{C}$ should have been formed during the sintering at $2173 \mathrm{~K}$ of $\mathrm{W}_{\mathrm{f}} / \mathrm{W}$ composites [19]. However, noticeably, the $\mathrm{WC}_{1-\mathrm{x}}$ and $\mathrm{WC}_{\mathrm{x}}$ are detected in the composites in this study. These kinds of carbides 
may have developed as the structural modifications of $\mathrm{W}_{2} \mathrm{C}$. The possible decomposition reaction at the high temperature may be:

$$
\mathrm{W}_{2} \mathrm{C} \leftrightarrow W C_{1-x}+W C_{x}
$$
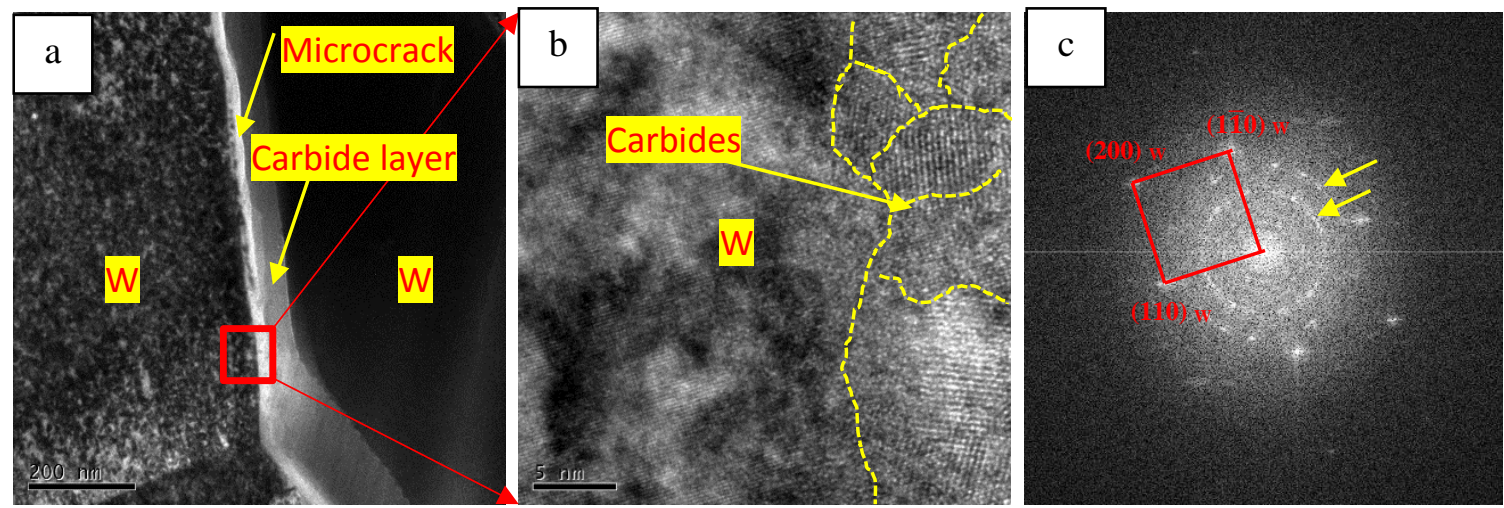

Fig. 4. (a) The TEM micrograph showing the carbides layer on the grain boundary. (b) An HRTEM image showing both the $\mathrm{W}$-matrix and carbides at the grain boundary in the red square from (a), the different grains of the carbides are separated by the dashed lines. (c) Diffractograms obtained by FFT of (b). The arrows show the diffraction rings from the $\{210\}$ and $\{222\}$ of $\mathrm{WC}_{\mathrm{x}}$.

The average carbon concentration in the tungsten fiber is difficult to analysis, as to separate the fiber and the matrix after sintering is quite challenging. The overall carbon concentration in the $\mathrm{W}_{\mathrm{f}} / \mathrm{W}$ is neglectable based on a combustion test. This means the carbon impurities are segregated in the tungsten fibers. This effect could be caused by the carbon which is interacted with the high density of dislocations, as shown in Fig. 3.

\section{Summary}

Three kinds of tungsten fiber reinforced tungsten $\left(\mathrm{W}_{\mathrm{f}} / \mathrm{W}\right)$ composites have been produced by using powder metallurgy processes in this study. It is found that carbon can cause the W-fiber 
embrittlement. The W-fibers in the samples which are not protected by tungsten foils lose its advanced ductility after sintering. The crystal structure of these carbides are determined to be fcc $\mathrm{WC}_{1-\mathrm{x}}$ in this study. This is the first time such carbides are clearly detected with the help of TEM analysis in W-fibers after powder-metallurgical treatment. Tungsten foil protection is an effective way to prevent the carbon diffusing into tungsten composites during sintering.

Tungsten is very sensitive to carbon. This conclusion dates already back to the 1960s [15]; and in tungsten industry, this is a common empirical knowledge. Currently, tungsten material studies are one of the most popular topic in the fusion material research field and strange brittleness issues of W-material are often reported. The carbon sensitivity of tungsten is however not anymore a common knowledge among fusion researchers. Although many reasons for the brittle behavior might be possible a common problem during the tungsten production is that the tungsten sample is not protected from graphite (carbon) during sintering or annealing. Therefore, based on the recent results on $\mathrm{W}_{\mathrm{f}} / \mathrm{W}$, the aim of this paper is to again draw the attention to the carbon issue for tungsten during production, post-treatment processes and application.

\section{Acknowledgment}

This work has been carried out within the framework of the EUROfusion Consortium and has

received funding from the Euratom research and training program 2014-2018 under grant agreement No. 633053. The views and opinions expressed herein do not necessarily reflect those of the European Commission.

\section{References}

[1] G. Pintsuk, I. Bobin-Vastra, S. Constans, P. Gavila, M. Rödig, B. Riccardi, Fusion Engineering and Design, 88 (2013) 1858-1861. 
[2] I. Smid, M. Akiba, G. Vieider, L. Plöchl, J. Nucl. Mater., 258-263 (1998) 160-172.

[3] Y. Mao, J.W. Coenen, J. Riesch, S. Sistla, J. Almanstotter, B. Jasper, A. Terra, T. Hoschen, H. Gietl, C. Linsmeier, C. Broeckmann, Compos Part a-Appl S, 107 (2018) 342-353.

[4] J.W. Coenen, Y. Mao, S. Sistla, J. Riesch, T. Hoeschen, C. Broeckmann, R. Neu, C. Linsmeier, Nuclear Materials and Energy, 15 (2018) 214-219.

[5] Y. Mao, J.W. Coenen, J. Riesch, S. Sistla, J. Almanstötter, B. Jasper, A. Terra, T. Höschen, H. Gietl, M. Bram, J. Gonzalez-Julian, C. Linsmeier, C. Broeckmann, Physica Scripta, T170 (2017) 014005.

[6] J. Riesch, J.Y. Buffiere, T. Höschen, M. di Michiel, M. Scheel, C. Linsmeier, J.H. You, Acta Materialia, 61 (2013) 7060-7071.

[7] H. Gietl, J. Riesch, J.W. Coenen, T. Hoschen, C. Linsmeier, R. Neu, Fusion Engineering And Design, 124 (2017) 396-400.

[8] J. Riesch, M. Aumann, J.W. Coenen, H. Gietl, G. Holzner, T. Höschen, P. Huber, M. Li, C. Linsmeier, R. Neu, Nuclear Materials and Energy, 9 (2016) 75-83.

[9] J.W. Coenen, Y. Mao, J. Almanstotter, A. Calvo, S. Sistla, H. Gietl, B. Jasper, J. Riesch, M. Rieth, G. Pintsuk, F. Klein, A. Litnovsky, A.V. Mueller, T. Wegener, J.H. You, C. Broeckmann, C. Garcia-Rosales, R. Neu, C. Linsmeier, Fusion Engineering And Design, 124 (2017) 964-968.

[10] R. Neu, J. Riesch, A.v. Müller, M. Balden, J.W. Coenen, H. Gietl, T. Höschen, M. Li, S. Wurster, J.H. You, Nuclear Materials and Energy, 12 (2017) 1308-1313.

[11] J. Riesch, Y. Han, J. Almanstotter, J.W. Coenen, T. Hoschen, B. Jasper, P. Zhao, C. Linsmeier, R. Neu, Physica Scripta, T167 (2016) 014006.

[12] A. Joshi, D.F. Stein, Metallurgical Transactions, 1 (1970) 2543-2546.

[13] E. Smiti, P. Jouffrey, A. Kobylanski, Scripta Metallurgica, 18 (1984) 673-676. 
[14] A.v. Müller, M. Ilg, H. Gietl, T. Höschen, R. Neu, G. Pintsuk, J. Riesch, U. Siefken, J.H. You, Nuclear Materials and Energy, 16 (2018) 163-167.

[15] J.R. Stephens, in, NATIONAL AERONAUTICS AND SPACE ADMINISTRATION CLEVELAND OH LEWIS RESEARCH CENTER, 1964.

[16] P. Zhao, J. Riesch, T. Hoschen, J. Almanstotter, M. Balden, J.W. Coenen, R. Himml, W.

Pantleon, U. von Toussaint, R. Neu, Int J Refract Met H, 68 (2017) 29-40.

[17] S. Chanthapan, A. Kulkarni, J. Singh, C. Haines, D. Kapoor, International Journal of Refractory Metals and Hard Materials, 31 (2012) 114-120.

[18] D. Scheiber, R. Pippan, P. Puschnig, L. Romaner, Modelling and Simulation in Materials Science and Engineering, 24 (2016) 085009.

[19] A.S. Kurlov, A.I. Gusev, Inorganic Materials, 42 (2006) 121-127. 